\title{
KONGRESSKALENDER
}

\section{November 2014}

19.-22.11.2014 San Francisco, California (USA) American Society of Criminology - Annual Meeting

Neglected Crimes, Groups, Causes and Policy Approaches

San Francisco Marriott Marquis

Information: http://www.asc41.com/annualmeeting.htm

\section{März 2015}

04.-06.03.2015, Lippstadt-Eickelborn

30. Eickelborner Fachtagung zu Fragen der Forensischen Psychiatrie

Kontaktadresse: Michaela.Riepe@wkp-lwl.org Information: www.lwl-forensik-lippstadt.de

\section{April 2015}

20.-22.04.2015, Potsdam-Griebnitzsee 17. Basiskurs Forensische Psychiatrie: Schuldfähigkeit, Maßregel, Prognose Prof. Dr. H.-L. Kröber

Institut für Forensische Psychiatrie der Charité Information: www.forensik-berlin.de

\section{Mai 2015}

08.05.2015, Wien, Allgemeines Krankenhaus Wien

9. Wiener Frühjahrstagung für Forensische Psychiatrie

Prof. Dr. Th. Stompe

Information: Yasmin Haunold, www.ce-management.com
15.05.2015, Dresden

20. Dresdner Frühjahrstagung für Forensische Psychiatrie

Dr. Lau, Dr. Lammel, Dr. Sutarski, Prof. Dr. Bauer

Information: www.forensik-dresden.de

\section{0.-22.05.2015, Zürich, Schweiz}

7. Internationales Symposium Forensische Psychiatrie

World Trade Center

Prof. Endrass, Dr. Rossegger, Prof. Urbaniok Information: www.forensiktagung.ch

\section{Juni 2015}

12.06.2015, Berlin-Dahlem

19. Berliner Junitagung für Forensische Psychiatrie und Psychologie

Institut für Forensische Psychiatrie der Charité

Information: www.forensik-berlin.de (Veranstaltungen)

16.06.-18.06.2015, Manchester, UK 15th Annual IAFMHS Conference Forensic Mental Health Services University of Manchester

Information: www.iafmhs.org

\section{Juli 2015}

12.-17.07.2015, Wien, Österreich 34th Congress of the IALMH International Academy of Law and Mental Health

Hotel Intercontinental

Information: www.ialmh.org

\section{Oktober 2015}

22.-25.10.2015, Fort Lauderdale, Florida (USA)

American Academy of Psychiatry and the Law

46th Annual Meeting (with APA)

Chicago Marriott Downtown

Information: www.AAPL.org

\section{November 2015}

18.-21.11.2015 Washington D.C. (USA) American Society of Criminology - Annual Meeting

Neglected Crimes, Groups, Causes and Policy Approaches

Information: http://www.asc41.com/annualmeeting.htm

Ein internationaler kriminologischer Kongresskalender findet sich unter http://www.asc41.com/caw.html

Hinweise für den Kongresskalender bitte an: hans-ludwig.kroeber@charite.de 